\title{
EL VERBO SER: CÓMO ORIENTAR LA COMUNICACIÓN
}

\section{THE VERB SER: HOW TO LEAD COMMUNICATION}

\section{Roberta Giordano*}

\section{RESUMEN}

El posicionamiento del verbo ser puede responder a una necesidad lógica y pragmáticodiscursiva, antes que lingüístico-formal precisa, con la que destacar, enfatizando, algún segmento oracional. Analizaremos el papel focalizador que la cópula desempeña, y, teniendo presente los contextos de uso, parangonaremos también el fenómeno sintáctico del hendimiento español con su correspondiente forma italiana, tratando de hacer emerger, así, las coincidencias y divergencias.

Reflexionaremos acerca de la gestión de las estructuras marcadas, en las que la dislocación de un segmento mediante la introducción de la cópula sirve para remarcar cierto dato informativamente relevante, y, por último, acerca de las ventajas de un uso didáctico de esta estrategia discursiva (E/LE).

Palabras clave: cópula, estructura informativa, énfasis.

\section{ABSTRACT}

The positioning of the verb ser corresponds to a logical and pragmatic-discursive necessity, before than linguistic-formal one, useful to emphasize some sentence constituent. We will analyze the focalizing role of the copula, and we will compare the spanish cleft sentences with their corresponding italian phrases too, trying to make emerge the coincidences and divergences.

Then, we will study the management of these marked structures, in which the dislocation of some of its elements serves to highligh the relevant informative core of the message. Finally, we will reflect on the advantages derived from a didactic use of this discourse strategy $(\mathrm{S} / \mathrm{FL})$. Keywords: copula, informative structure, emphasis.

\section{PREMISAS}

Nuestro punto de partida son las conclusiones de un trabajo que recientemente escribimos sobre el papel de la competencia pragmática intercultural y de cómo sería posible explotarla en el aula de Español como Lengua Extranjera (E/LE), para acostumbrar a los estudiantes a seleccionar el posicionamiento de los segmentos oracionales de acuerdo con el contexto y el propósito comunicativo concreto también.

* Università degli Studi della Tuscia, Viterbo, Itália. roberta.giordano@unitus.it, https://orcid. org/0000-0002-5900-7982 
En dicho ensayo se ha reflexionado sobre la importancia de la estructura informativa para construir y vehicular los mensajes adecuándolos no solo a convenciones, moldes formales y esquemas fijos impuestos por las reglas gramaticales, sino también a necesidades pragmáticas vinculantes.

Llegamos a la conclusión, así, que la estructura informativa responde a finalidades interaccionales precisas, de ahí que mediante la alteración de sus segmentos se exalte el dato más significativo para el interlocutor: se trata de una enorme potencialidad expresiva, al mismo tiempo instrumento de dinamización del aprendizaje, con el que concienciarse y autonomizarse en el uso de la lengua extranjera.

Además, desde una perspectiva comparativa es imprescindible poner el foco en el hecho que la afinidad español-italiano transparece también del modo en el que las dos lenguas organizan su arquitectura oracional, nos referimos a dos patrones fundamentales: en primer lugar, el posicionamiento de la información nueva hacia el final del enunciado y la conocida al inicio, y, en segundo lugar, la previsión de oraciones con sujeto tácito (sottinteso), condición preliminar esta última que, ya por sí misma permite una inversión bastante libre del sujeto.

Al mismo tiempo, si desde un punto de vista pragmático la segmentación interna de las unidades sintácticas consiente entender inequívocamente el valor de sus constituyentes, desde uno teórico estamos midiéndonos con un tema muy vasto y deslizadero, dado el sinfín de definiciones e interpretaciones existente acerca de la estructura informativa (tema, tópico, soporte, figura, rema, foco, aporte, comentario, fondo, etc.).

Fíjense, por ejemplo, en el binomio tema y tópico. Aplicando la definición de la Nueva Gramática de la Lengua Española - NGLE ("el tópico incluye los segmentos temáticos destacados o desgajados de la oración") (REAL ACADEMIA ESPAÑOLA, 2009, p. 2972) al comentario del segmento periódico dentro de las frases "El periódico lo compra mi padre"/"El periódico, lo compra mi padre", se nota que mientras en la primera el sintagma desarrolla la función de tema, el asunto sobre el que se habla, en la segunda, donde el término está extrapuesto a la izquierda mediante una coma, este funciona de tópico, explicitando de qué se habla. (DEL BARRIO DE LA ROSA, 2015, p. 1285)

Otra engañosa confusión es la que a menudo se produce entre rema y foco, llevando así a errores comunicativamente graves: mientras el primero alude a la información novedosa aportada por el enunciado, el segundo indica el realce informativo que se quiere darle a cierto segmento del enunciado, pudiendo 
concluirse que no toda información novedosa coincide automáticamente con el foco. (LAMBRECHT, 1994)

Una última y no muy sutil diferencia es la que existe entre la presuposición y el foco: mientras la presuposición (o tema), que se halla dentro de la cláusula de relativo, brinda una información ya poseída por emisor y receptor, el foco, que puede coincidir o menos con el rema y se halla en el segmento enfatizado, lleva la información más relevante de la oración, la que el emisor considera esencial transferirle a su interlocutor, concentrando en esta la prominencia informativa del mensaje. (FANT, 1984)

Hechas estas consideraciones preliminares, se pretenderá aplicarlas al plano didáctico, convencidos del hecho que este tema puede ser muy ventajoso para el aula, dado que la estructura informativa conlleva una doble perspectiva de análisis: sintáctica y discursiva. Si, atendiendo a la primera, la frase "Los libros los ha pagado mi madre" representaría una variante marcada de la no marcada "Mi madre ha pagado los libros", atendiendo a la segunda, en cambio, nos estaríamos frente a dos frases y dos formas completamente distintas de organizar las informaciones. Si el enfoque sintáctico, en efecto, distingue entre enunciados neutros y marcados, para el informativo ni siquiera existirían enunciados totalmente neutros, siendo siempre la organización de sus constituyentes el reflejo del valor informativo global.

Respecto a este tema ya desde hace mucho está eclosionando una nueva orientación por parte de las gramáticas de referencia, sobre todo las españolas. Se trata de una interpretación novedosa de las funciones informativas: ya no un apéndice del más vasto tema de la estructura oracional, sino más bien uno dotado ahora de fisionomía propia, al que dedicarle capítulos enteros y secciones específicas.

Sin embargo, como Leonetti (2014) subraya, antes de ser un tema de orden pragmático, la estructura informativa queda uno gramatical, que englobaría la vertiente semántica y la fonética también, tesis corroborada por la existencia de normas y restricciones rigurosas para el orden de sus constituyentes. Dentro de los límites impuestos por las convenciones gramaticales, por lo tanto, y coherentemente con los datos ya previamente compartidos (o menos) por los interlocutores, se trata ahora de entender cómo combinar estas dos perspectivas, moldeando la disposición oracional conforme a las necesidades de orden pragmático y comunicativo también.

\section{EL HENDIMIENTO}

El hendimiento (traducción del término inglés cleaving) es una estrategia discursiva usada bastante comúnmente tanto en español como en italiano también, 
a la que se recurre cuando se quiere destacar informativamente cierto elemento o dato, obtenida repartiendo el material léxico de la cláusula en dos bloques distintos mediante la inserción de dos marcadores estructurales, el verbo ser y un enlace hipotáctico (relativo o conjunción):

uno de los recursos sintácticos más comunes con los que la lengua española destaca cierta información aportada por la oración. Desde el punto de vista sintáctico, una escindida consiste en un elemento extrapuesto (en obras generativistas llamado "foco"), ligado mediante una forma de la cópula ser al resto de la oración ("la presuposición"), el cual aparece en forma de una relativa independiente. (FANT, 1984, p. 131)

Las oraciones derivantes de este proceso de alteración de la forma canónica de la frase mediante la dislocación de algunos de sus elementos, así, vienen definidas bendidas (escindidas o ecuacionales). Más detalladamente, el término bendida viene aplicado a todas las copulativas focalizantes complejas del español, en las que no son contiguas palabras que sí lo serían dentro de la no-hendida correspondiente, cuyos elementos constitutivos son: 1 . la cópula $(\mathrm{S})$; 2. el foco $(\mathrm{F}) ; 3$. un sintagma, con una relativa, con una información supuestamente verdadera $(\mathrm{P})$.

Sobre el origen de esta construcción, vale la pena recordar que se han generalizado mucho los términos hendidas y escindidas, a partir del inglés cleft dado por Jespersen en 1924. En los años sucesivos fueron introducidas muchas otras definiciones más: perífrasis de relativo y fórmulas perifrásticas de relativo por Fernández Ramírez (1951), Ortega Olivares (1988) y Moreno Cabrera (1983, 1999); estructuras ecuacionales por Alarcos (1970); estructuras bendidadas o escindidas (pseudobendidas o pseudoescindidas) por D'Introno (1979). (MORENO CABRERA, 2009, p. 4228)

Luego, la Nueva Gramática de la Lengua Española (RAE, 2009) las habría denominado copulativas enfáticas, mientras Gutiérrez Ordóñez las habría repartido en las siguientes taxonomías: ecuacionales plenas ("Ayer fue cuando Ana lo dijo", "Fue ayer cuando Ana lo dijo", "Cuando Ana lo dijo fue ayer"); ecuacionales galicadas ("Ayer fue que lo dijo Ana", "Fue ayer que lo dijo Ana"), ecuacionales escuetas ("Ana lo dijo fue ayer"), ecuandicionales ("Si en algún momento Ana lo dijo fue ayer"). (GUTIÉRREZ ORDÓÑEZ, 2015, pp. 16-17)

Teniendo en consideración este cuadro teórico de referencia y con arreglo a los datos extraídos del corpus redactado por Sedano, la frase no marcada "Juan necesita descanso" originaría las siguientes tres opciones hendidas correspondientes:

1. "Es un descanso lo que Juan necesita" (hendida),

2. "Lo que Juan necesita es un descanso" (pseudohendida), 
3. "Un descanso es lo que Juan necesita" (pseudohendida inversa). (SEDANO, 2010, p. 41)

De los ejemplos arriba citados resulta explícito que en la estructura pseudohendida la cláusula relativa contiene una información variable, o, mejor dicho, incógnita (lo que Juan necesita), que comprende a su vez el foco informativo también (el descanso).

De esta reflexión, además, procede otra aún más llamativa: desde una perspectiva pragmática se aprecia la mayor carga expresiva del hendimiento, porque la oración ortodoxa correspondiente ("Juan necesita descanso") sería mucho menos comunicativamente eficaz respecto al segmento bajo foco, consintiendo también exaltar el valor contrastivo del constituyente focalizado respecto al contenido de la cláusula. (SEDANO, 2010, p. 42)

Así, a diferencia de lo que ocurre dentro de una estructura no marcada, dentro de la marcada el elemento focalizado tiende a ocupar la posición inicial. La focalización, que implícitamente el hendimiento conlleva, es un recurso discursivo con el que la dislocación satisface una necesidad lógica y discursiva a la vez: repartir y organizar los conocimientos previos para guiar, adecuadamente, la interpretación de los novedosos por parte del receptor.

Por lo que se refiere a la naturaleza del verbo ser, en particular, Sedano hace notar como entre los expertos (sobre todo Bosque) se baraja la hipótesis según la que en estas construcciones la cópula no funcionaría como un verbo propiamente dicho, sino como una partícula destinada a la configuración estructural de las frases, con el objetivo de realzar informativamente el constituyente bajo foco y su unicidad (o contrastividad) también. (SEDANO, 2010, p. 39)

Además, la necesidad de puntualizar, distinguiendo, lleva al uso de conectivos de tipo anafórico, con los que se construyen enlaces paratácticos entre las cláusulas. Se trata de una estrategia muy frecuente sobre todo en la lengua hablada, mientras que, como es bien sabido, en la lengua escrita predomina la subordinación: a menudo, se emplea el conector es que.

Totalmente gramaticalizada, así, la forma es que desarrolla el papel de modalizador o de contraste respecto a un razonamiento previo ("No, no es que no me guste", "A mí no me escandaliza que entre con el filito...Pero lo que más me espanta es que haya unas chicas monísimas, jovencitas, con unos viejos que se caen a pedazos"), útil para transmitir un creciente grado de énfasis ("tengo prisa"/"que tengo prisa"/"es que tengo prisa") y para explicitar la naturaleza asertiva de la oración. Se trata de un conector usado también en interrogativas directas e indirectas ("No sé si es que lo editan ni dónde están") y con un marcado valor 
potencial ("son los profesionales que tardan diez años en ponerse en órbita....si es que se ponen alguna vez"). (DI TULLIO, 1990, pp. 13-14)

En estos casos, precisa Martínez (1994), no sería correcto hablar de copulativas canónicas, en primer lugar porque las hendidas no se fundamentan en la pareja sujeto-atributo, mientras el verbo ser ayuda a definir la estructura focalizadora, y, en segundo lugar, porque, como precisa López García (1996) también, las expresiones copulativas canónicas no son enfáticas, ni tampoco las relativas. (SEDANO, 2010, p. 42)

Moreno Cabrera (2009) coincide con esta interpretación y define una oración como "Es Juan el que ha llegado tarde" una perífrasis de relativo, un rodeo correspondiente a la no hendida "Juan ha llegado tarde", o, sea, una relativa "libre", una frase subordinada relativa desgajada de otro sintagma, es decir, sin antecedente.

Dirigiéndonos en nuestra labor cotidiana a estudiantes italófonos, nos parece oportuno confrontar estos mecanismos con los de enfatización correspondientes accionados en la lengua italiana:

Una frase scissa (FS) è una struttura frasale complessa costituita da una frase principale copulativa con verbo essere a soggetto nullo o espletivo, e da una subordinata dipendente dall'argomento della copula. Semanticamente, principale e subordinata nel loro insieme esprimono una proposizione logicamente semplice, che può essere enunciata sotto forma di un'unica frase senza che questo provochi cambiamenti nelle condizioni di verità. Informativamente, la funzione della FS è quella di isolare l'argomento della copula (elemento scisso) come focus dell'enunciato e la subordinata come contenuto presupposto. (ROGGIA, 2008, p. 11)

A partir del corpus oral bilingüe italiano-francés C-ORAL-ROM, Roggia detecta algunas tipologías principales de frasi scisse atendiendo a la función discursiva concreta que la cópula desempeña en cada construcción: prototipica ("é la nebbia che mi fa paura"); con pronome relativo ("era questo a cui ti riferivi?"); temporale ("sono due anni che non lo vedo"); implicita ("è stato Mario a raccontarmi tutto"); interrogativa ("chi è che l'ha detto?", "a chi è che devo rivolgermi?"). (ROGGIA, 2008, p. 11)

Volviendo a un paradigma precedentemente mencionado, el conector (no) es que, es curioso observar comparativamente que, de acuerdo con el Lessico di frequenza dell'italiano parlato-LIP- (DE MAURO et alii, 1993) en italiano resultaría numéricamente predominante la focalización de la negación (non è che), estructura en la que la litote contribuye a mitigar, o circunstanciar mejor, afirmaciones anteriores propias o de los interlocutores ("io non è che sono proprio sveglia, però scema del tutto non ci sono"). (D’ACHILLE; PROIETTI; VIVIANI, 2005, p. 266)

Siguiendo con lo de la contrastividad, además, añadimos que las diferentes lenguas tratan el hendimiento de maneras muy distintas: mientras en inglés y en 
francés viene considerada una manifestación de la lengua estándar, o sea, descrita en las gramáticas de referencia, en italiano la frase scissa viene definida un tratto neostandard o dell'uso medio:

A torto o a ragione la scissa in italiano è generalmente ritenuta un francesismo di diffusione settecentesca. I grammatici francesi sono stati del resto i primi a dare una descrizione del costrutto (Grammaire générale et raisonnée di Arnauld y Lancelot, 1660) e i primi a considerarlo fin dal Settecento (e ancora in Léard 1992) un "gallicismo", cioè una struttura idiomatica propria e caratterizzante della sintassi francese. (ROGGIA, 2008, p. 10)

Ya en 1985, en efecto, Sabatini señalaba que dicha construcción era casi siempre ignorada por la tradición gramatical y lexicográfica italiana, prefiriendo definirla un galicismo, llevando a autores partidarios de una visión castiza y conservadora de la lengua italiana, como Gabrielli y Messina, a expresarse de un modo muy crítico:

Essere (verbo): si presta a costrutti e ad espressioni riprese dei puristi perché brutti gall[icismi] facilmente evitabili. Il costrutto è....che (è a voi che parlo) è inutile (parlo a voi, parlo proprio a voi) anche quando si accompagna a per questo (è per questo che son venuto: son venuto proprio per questo), tranne nei casi in cui che è pronome relativo (fu lui che parlò per primo) (Messina, 1965, 147). Invece, non creano problemi normativi le frasi pseudoscisse invertite (chi mi manca è lui, questo è quello che dici tu) formalmente identiche alle normali sequenze copulari, dove il che appare più nettamente come pronome relativo. (D'ACHILLE; PROIETTI, VIVIANI, 2005, pp. 250-251)

De todas formas, por el momento nos limitamos a estas pocas y no exhaustivas consideraciones de carácter contrastivo español-italiano, tratándose de una dimensión que merecería, en cambio, un estudio aparte.

\section{LAS POTENCIALIDADES PARA EL AULA DE E/LE}

Antes de abordar el tema del empleo didáctico del hendimiento es oportuno tener presente que tanto en español como en italiano a través de esta construcción se puede focalizar todo tipo de elemento y función sintáctica: a partir de los sintagmas nominales ("Es su biografía la que han publicado recientemente"/"È la sua biografia che è stata pubblicata di recente"); sintagmas preposicionales en función de complemento indirecto ("Es al portero (al que, a quien) hay que entregar las cartas" /"È al portiere che bisogna consegnare le lettere"); preposicional ("Es de María (la que, quien) os podéis fiar"/"È di Maria che vi potete fidare") y circunstancial ("Es en el patio donde puedes jugar con la arena"/"È nel cortile che puoi giocare con la sabbia"); adverbios en función de complemento circunstancial 
de tiempo ("Es mañana cuando le otorgan el premio"/"È domani che gli viene consegnato il premio") y adjetivos en función de complemento predicativo ("Es gordo como se ha vuelto tu sobrino"/"È grasso che è diventato tuo nipote"; "Es desaparecido como no puede estar"/"È sparito che non può essere"); hasta llegar al infinitivo ("Es levantarse lo que no quiere"/"Ė alzarsi che non vuole") y al gerundio ("Es comiendo como te harás fuerte"/"Ė mangiando che diventerai forte"). (DEL BARRIO DE LA ROSA, 2015, p. 1301)

Estas evidentes capacidades expresivas nos hacen entrever en la implementación en el aula de E/LE de actividades orientadas a la explotación de destrezas relacionadas con la estructura informativa en general dos ventajas fundamentales, una directa de corte pragmático y otra indirecta de corte sintáctico: la primera, porque estas actividades mostrarían a los aprendices cómo orientar la frase de acuerdo con el objetivo comunicativo y los interlocutores; la segunda, porque estas enseñarían cómo medirse con los mecanismos formales también implícitamente englobados en la estructura informativa, como la adecuación morfosintáctica y las estrategias de concordancia, de no siempre fácil gestión.

Del Barrio de la Rosa $(2015$, p. 1301) profundiza el análisis de estos mecanismos desde una perspectiva contrastiva con el italiano, centrándose en particular en su repercusión en la concordancia: 1 . cuando el segmento focalizado es un pronombre personal mientras los verbo ser/essere concuerdan con el segmento focalizado, el verbo de la relativa solo en español puede concordar sea con el pronombre relativo sea con el elemento focalizado ("Soy yo el que te ha/he elegido"/"Sono io che ti ho scelto/a scegliere te"), y esto debido al hecho que el che italiano no funciona como pronombre relativo, sino solo como conjunción; 2 . el verbo copulativo fija una relación de identificación entre el segmento focalizado y la oración de relativo, que se establece en el momento del habla, de ahí que la cópula venga conjugada siempre en presente ("Es en esta calle donde viví los primeros años" / "È in questa strada che abitai i primi anni"); 3. mientras en italiano el tiempo essere queda independiente del de la oración subordinada, a no ser que se desee focalizar la marca temporal ("Fu il mese scorso che sei stato avvisato"), en español el tiempo verbal de la subordinada podría influir también en el de la cópula ("Fue en esta calle donde viví los primeros años").

Por lo que atañe a la vertiente pragmática Moreno Cabrera (2009) hace hincapié en el uso discursivo de las que él denomina perífrasis de relativo, demostrando que la alteración del orden de los constituyentes oracionales y de la puntuación pueden modificar, y de una manera muy incisiva también, el significado mismo de los enunciados. 
Durante el año pasado (2017) todas estas reflexiones nos convencieron de la validez del uso de la estructura informativa y de las técnicas de alteración y enfatización correlatas para un curso universitario de primer año de Lingua e traduzione - Lingua spagnola dirigido a estudiantes italófonos. Así, antes de la ejecución de nuestro proyecto didáctico, adelantamos en nuestra aula de E/LE algunas actividades preparatorias de ayuda para las tareas finales. Decidimos exponer a los estudiantes a toda forma de contacto directo con la lengua y la cultura extranjeras, sirviéndonos de grabaciones, prensa y materiales auténticos y de intercambios reales con nativos hispanohablantes, sobre todo con los llegados a Italia en el ámbito del proyecto Erasmus.

Así, tras haber seleccionado algunos textos dialógicos de manuales, periódicos, vídeos y fórum en lengua española, se les pidió a los aprendices que transformasen en hendidas algunas frases no marcadas presentes en los materiales sometidos durante el curso, atreviéndose a modificar su sentido a medida que se modificaba su estructura.

Estas actividades, cuyo cumplimiento necesitó mucha atención respecto también a su perfil sintáctico, como se evidenciaba antes (fíjense, por ejemplo, en los inconvenientes que el hendimiento puede conllevar respecto a la concordancia en persona y en tiempo verbal de los elementos oracionales), luego presentadas y explicadas a la clase, fueron objeto de una larga discusión de grupo en la que cada estudiante tuvo que comentar y argumentar sobre las elecciones emprendidas y sobre las razones, tanto de orden formal-gramatical como pragmático, que habían llevado a las construcciones finales.

Proponemos a continuación una muestra de ejemplos extraídos del experimento. Para cada una de las frases escogidas los aprendices debieron demostrar si y cómo el cambiante propósito comunicativo de cada mensaje incidía en la estructura final:

1) "Al principio pensé poder contar en el apoyo de mis mejores amigos, pero al final tuve que convencerme de lo contrario. Tenemos que confiar solo en nuestras fuerzas y capacidades!",

1.1 "Es, solo, en nuestras fuerzas y capacidades que tenemos que confiar",

1.2 "Son solo nuestras fuerzas y capacidades las en que (en las que) tenemos que confiar".

2) "Puede que Luis o Enrique me lo haya dicho...",

2.1 "Es Luis el que me lo ha dicho",

2.2 "Luis es el que me lo dicho", 
2.3 "El que me lo ha dicho es Luis",

2.4 "Si me lo ha dicho alguien es Luis".

3) "Desde hace dos horas quedo en la espera de Luis...no sé qué le ha ocurrido",

3.1 "iPues claro que no llegó! Luis te avisó ayer",

3.2 "iPues claro que no llegó! Fue ayer que Luis te avisó",

3.3 "iPues claro que no llegó! Ayer fue que Luis te avisó".

4) "Fue la cosa más importante que hice por su vida",

4.1 "No, no lo hiciste por su vida, es que lo hiciste por tu felicidad",

4.2 "No, no lo hiciste por su vida, por tu felicidad fue que lo hiciste",

4.3 "No, no lo hiciste por su vida, fue por tu felicidad por lo que lo hiciste",

4.4 "Si por algo lo hiciste, fue por tu felicidad".

Como se explicaba antes, la segunda fase del experimento consistió en justificar las elecciones emprendidas y, al analizarlas, se nota como cada una de ellas sugiere una idea de hendimiento coherente con objetivos comunicativos específicos, que la forma $\mathrm{y}$, sobre todo, la función discursiva de las estructuras marcadas, fielmente ha respetado. Más concretamente, se puede apreciar que en el primer grupo de enunciados predomina la función especificativa, con la que se aclara cierto dominio conceptual; en el segundo grupo, prevalece la función posespecificativodecisoria, con la que el hablante asume cierta posición hacia una situación dudosa o controvertida; en el tercer grupo, sobresale la función posespecificativo-enfática, mediante la que se explica, pero sin nunca contradecirla, la razón del acontecimiento referido en la frase de partida, insistiendo bien en el verbo ser, bien en el adverbio temporal ayer; en el último grupo la función posespecificativo-rectificativa se explicita en el verbo ser, encargado de la tarea de corregir cierta afirmación de abertura. (DEL BARRIO DE LA ROSA, 2015, p. 4229)

La conclusión más interesante de nuestro experimento es que la organización de las frases tiende a cambiar a medida que cambia la necesidad comunicativa, hasta modularse, exactamente, conforme a ella. Todas las construcciones analizadas durante nuestras actividades didácticas giran constantemente alrededor de la cópula, necesitándola para potenciar el significado del mensaje. Esto demuestra que, funcionando de apoyo estructural para las nuevas arquitecturas lógico-expresivas y mediante dislocaciones ponderadas, el verbo ser posee enormes potencialidades discursivas: no solo explicitación de los conceptos, sino también orientación de los receptores, hasta recurrir al efecto irónico-sarcástico que una construcción ecuandicional puede producir ("Si por algo lo hiciste, fue por tu felicidad"). 
Además, no se puede prescindir del hecho que a menudo durante la ejecución de sus tareas nuestros estudiantes optaron por una o por otra forma porque condicionados por su lengua de origen. Es evidente, en efecto, que las oraciones marcadas a menudo reproducían las que habitualmente se pronunciarían en italiano, así como demuestra el recurso al conector es que/è che y a la ecuandicional ("No, no lo hiciste por su vida, es que lo hiciste por tu felicidad"/ "No, non lo facesti per la sua vita, è che lo hai fatto per la tua felicità"; "Si por algo lo hiciste, fue por tu felicidad"/ "Se per qualche ragione lo hai fatto, lo hai fatto per la tua felicità").

Por último, tal como en italiano, frecuentemente se aumentó el énfasis de los enunciados, insistiendo en los rasgos específicos de algunas informaciones referidas, como la exclusividad, operación facilitada por un uso atentísimo de la puntuación ("Es, solo, en nuestras fuerzas y capacidades que tenemeos que confiar"/"È, solo, nelle nostre forze e capacità che dobbiamo confidare").

\section{CONCLUSIONES}

Las estructuras aquí analizadas son funcionales a la concretización de una intención lingüística y pragmática estratégica: saber evaluar y evidenciar, de ahí orientándolos, informaciones, características y matices.

Dar la cara con soltura a estos mecanismos discursivos puede constituir el acmé de un proceso educativo en el que, dejando de lado la exclusividad de las reglas, y sirviéndose también de herramientas como los marcadores, las implicaturas, las rutinas, los actos de habla, se exploten habilidades de orden pragmático relevantísimas: nos referimos a la adquisición de agilidad respecto a funciones clave, como argumentar, justificar, convencer, mitigar las peticiones, contrastar, etc. (YOSHIMI, 2001)

Este mecanismo, explotable a largo plazo, permite desbrozar no solo la relación entre gramática y pragmática, sino también la entre language socialization y teoría sociocognitiva (KASPER, 2000): para ambas la adquisición de la lengua y la cultura y el desarrollo cognitivo dependerían de la interacción social que se produce en concretos contextos sociohistóricos. Se rechaza completamente, de esta manera, la idea de un aprendizaje como conjunto de representaciones intrapsicológicas individuales, defendiendo, en cambio, la de uno entendido como resultado de un fenómeno creativo y de intercambios constantes.

A partir de los resultados recogidos de nuestro experimento hemos llegado a la conclusión que el hendimiento y toda forma de focalización pueden llevar a la maduración de una actitud nueva hacia la lengua, acreciendo la facilitad, 
prontitud y gracia individual en las interacciones cotidianas, lo que, coadyuvado por el uso de soportes como grabaciones y materiales auténticos también (OHTA, 1995; KANAGY, 1995), puede abrir escenarios novedosos hacia una reflexión metalingüística y metapragmática provechosas.

Al mismo tiempo, pensamos que la estructura informativa en general representa una línea de investigación también muy estimulante, con la que experimentar una reorganización profunda de todas las disciplinas involucradas, considerándolas partes integrantes de un único proyecto global. Aludimos al experimento desarrollado por Fuentes Rodríguez $(I+D+I$ MesA Microsintaxis del español actual. El enunciado: estructura y relaciones), que, poniendo especial atención en la modalidad, la focalización, la argumentación y la enunciación, trata de unir el análisis sintáctico y el pragmático, para crear la macrosintaxis o gramática discursiva del español. (FUENTES RODRÍGUEZ, 2017, pp. 2-3)

Se trata de un ámbito de estudio y aplicativo muy fructífero: la idea de centrarse en el papel focalizador de la cópula, en efecto, ha confirmado que la integración definitiva entre gramática y pragmática puede ser la respuesta más eficaz para un aprendizaje que necesita ahora enfoques multidimensionales y multidisciplinares. Nuestra propuesta ha tratado de demostrar que un segmento formal de la oración como el verbo ser puede desempeñar un rol pragmático crucial, dándoles a los mensajes valores multiformes:

En las hendidas el verbo ser funciona más bien como un expediente sintáctico que contribuye a realzar el elemento antepuesto, no queda aquí ningún resto de correlato semántico. En el caso del que galicado ${ }^{1}$ este mayor grado de gramaticalización se hace aún más evidente: SER-QUE, elementos meramente gramaticales, sin sustancia semántica y átonos, funcionan como pinza que rodea al foco. En su máximo grado de gramaticalización, la forma ES QUE ha perdido casi su variación temporal y modal ("Es que se me cerraron una cantidad de caminos"). (DI TULLIO, 1990, pp. 9-10)

La idea de emplear este tipo de instrumentos para el aprendizaje de una lengua extranjera se mueve precisamente en la nueva dirección adelantada por Fuentes Rodríguez (2017), en la que los planos distintos se imbrican, las dimensiones supuestamente divergentes se acercan entrecruzándose, promoviendo un crecimiento individual que incorpore las aportaciones provenientes de áreas

1. El llamado que galicado, aunque actualmente su afiliación francesa ha sido cuestionada, es un fenómeno muy extendido en el español de América y bien estudiado entre otros por Sedano (1999; 2010), Navarro (1998) y Dufter (2010). Se trata del que que sustituye en la mayoría de los casos a los pronombres de causa, modo, tiempo y lugar en construcciones escindidas como "fue allí que lo vi", "fue por eso que se lo dije". (Borreguero Zuloaga, 2015, p. 105). 
heterogéneas, para la construcción de un nuevo diseño gramatical futuro y, sobre todo, para una renovación cultural y educativa profunda.

\section{REFERENCIAS}

ALARCOS, E. (1970). Estudios de gramática funcional del Español, Madrid: Gredos.

BORREGUERO ZULOAGA, M. (2015). El gato, que ha tirado un vaso: ¿construcciones escindidas en el español coloquial?, Revista internacional de lingüística iberoamericana, XIII, 2 (26), pp. 101-122.

D'ACHILLE, P.;PROIETTI, D.jVIVIANI, A. (2005). La frase scissa in italiano: aspetti e problemi, in Tipologia linguistica e società. Considerazioni inter e intralinguistiche. Due Giornate italo-danesi di studi linguistici (Roma, 27-28 novembre 2003), al cuidado de I. Korzen \& P. D’Achille, Firenze: Cesati, pp. 249-279.

DEL BARRIO DE LA ROSA, F. (2015). Las funciones informativas, in GREIT Gramática de referencia de español para italófonos (dir. Félix San Vicente), Salamanca: CLUEB Universidad de Salamanca, pp. 1277-1307.

DE MAURO, T. et alii (1993). Lessico di frequenza dell' italiano parlato. Milano: EtasLibri.

D'INTRONO, F. (1979). Sintaxis transformacional del Español, Madrid: Cátedra.

DI TULLIO, Á. (1990). Sobre hendidas y pseudohendidas, Revista de Lengua y Literatura, 7, pp. 3-16.

DUFTER, A. (2010). El que galicado: distribución y descripción gramatical, in La 'excepción' en la gramática española. Perspectivas de análisis (A. Zamorano Aguilar; C. Sinner eds.), Madrid \& Frankfurt: Iberoamericana Vervuert, pp. 253-278.

FANT, L. (1984). Estructura informativa en español: estudio sintáctico y entonativo. Estocolmo, Uppsala: Almqvist \& Wiksell.

FERNÁNDEZ RAMÍREZ, S. (1951). Gramática española 4. El verbo y la oración, Madrid: Arco Libros.

FUENTES RODRÍGUEZ, C. (2017). (I+D+I MesA Microsintaxis del español actual). El enunciado: estructura y relaciones, Linguiistica en la red, 14. 
GUTIÉRREZ ORDÓÑEZ, S. (2015). La familia de las ecuacionales, Revista internacional de lingüística iberoamericana, XIII, 2 (26), pp. 15-37.

JESPERSEN, O. (1924). The Philosopby of Grammar, Chicago and London: The University of Chicago Press.

KANAGY, R. (1995). Interactional routines as a mechanism for L2 acquisition and socialization in an immersion context, Journal of Pragmatics, 31, pp. 1467-1492.

KASPER, G. (2000). Four perspectives on L2 pragmatic development, in Annual Conference of the American Association of Applied Linguistics, Vancouver, pp. 1-46.

LAMBRECHT, K. (1994). Information Structure and Sentence Form: Topic, Focus and the Representation of Discourse Referents. Cambridge: Cambridge University Press.

LEONETTI, M. (2014). Gramática y pragmática en el orden de palabras, Lingüística en la red, 12, pp. $1-25$.

LÓPEZ GARCÍA, A. (1996). Gramática del español, Madrid: Arco/Libros.

MARTÍNEZ, J.A. (1994). Cuestiones marginadas de gramática española, Madrid: Istmo.

MORENO CABRERA, J. C. (1999). Las funciones informativas: las perífrasis de relativo, in I. Bosque, V. Demonte (Eds.), Gramática descriptiva de la lengua española, Madrid: Espasa Calpe, pp. 4245-4302.

MORENO CABRERA, J. C. (1983). Las perífrasis de relativo, in Serta Pbilologica F. Lázaro Carreter, Madrid: Cátedra, pp. 455-467.

NAVARRO, M. (1998). El uso del que galicado en el habla de Valencia, Thesaurus, 53, pp. $575-581$.

OHTA, A. (1995). Applying sociocultural theory to an analysis of learner discourse: learnerlearner collaborative interaction in the zone of proximal development, Issues in Applied Linguistics, 6, pp. 93-121.

ORTEGA OLIVARES, J. (1988). Observaciones sobre las «fórmulas perifrásticas de relativo» in VV.AA., Studia Lilteraria atque Lingüistica, Granada, pp. 185-210.

REAL ACADEMIA ESPAÑOLA, (2009). Nueva gramática de la Lengua Española, Madrid: ESPASA. 
ROGGIA, C. E. (2008). Frasi scisse in italiano e francese orale: evidenze dal C-ORALROM, Cuadernos de Filología italiana, 15, pp. 9-29.

SABATINI, F. (1985). L'italiano dell'uso medio: una realtà tra le varietà linguistiche italiane, in G. Holtus, E. Radtke (al cuidado de), Gesprochenes Italienisch in Geschicbte und Gegenwart, Tübingen:Gunter Narr Verlag, pp. 154-184.

SEDANO, M. (2010). El verbo ser en las oraciones pseudohendidas y con el verbo ser focalizador, Nueva Revista de Filología Hispánica, 58, 1, pp. 39-58.

SEDANO, M. (1999). El uso del llamado que galicado: posibles explicaciones, in Actas del VIII Congreso internacional de la Asociación de Linguística y Filología de la América Latina (1987, San Miguel de Tucumán): Universidad Nacional de Tucumán.

YOSHIMI, D.R. (2001). The instruction of discourse markers in an intermediate Japanese foreign language classroom, in K. Rose, G. Kasper, Pragmatics in language teaching, New York: Cambridge University Press, pp. 223-244.

Recebido: 19/11/2018

Aceito: $25 / 04 / 2019$

Publicado: 10/06/2019 